\title{
Assessment of Physical Functional Status Among Patients with Hip Osteoarthritis
}

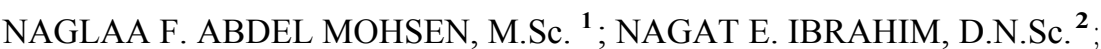 \\ LAMIA MOHAMED - NABIL ISMAIL, D.N.Sc. ${ }^{3}$ and HEBA A. MOSTAFA, D.N.Sc. ${ }^{4}$ \\ The Deprartments of Megdical Surgical Nursing ${ }^{1,2,4}$ and Nursing Education ${ }^{3}$, Faculties of Nursing, \\ Fayoum and Cairo ${ }^{2,3}$ Universities
}

\begin{abstract}
Background: Hip osteoarthritis is the most common joint disorder among old age individuals above the age of 60. It is painful and disabling diseases which are characterized by pain, stiffness, loss of joint function, difficulty moving and loss of muscle strength. Increasing the negative effects on hip joint leads to deterioration of the physical function and quality of life in individuals.

Aim: The aim of the study was to assess physical functional status among patients with hip osteoarthritis. Research question: What is the physical functional status of patients with hip osteoarthritis?
\end{abstract}

Material and Methods: Descriptive study design was utilized to achieve the aim of the study. Adult male and female conscious patients diagnosed with hip osteoarthritis, not on rehabilitation program were recruited for this study. The study was carried out in the orthopedic outpatient clinic, rheumatoid and the orthopedic inpatients ward at Fayoum university hospitals in Fayoum governorate. Structured interview questionnaire and WOMAC index including pain, stiffness and physical function were used for data collection.

Results: There was the statistically significant correlation between total pain score, stiffness score and total physical function score with $(r=0.416$ and 0.364$)$ respectively. It can be concluded that results of the current study showed that high scores of difficulties in different day to day physical function activities that affect on the patient life and work performance.

Recommendation: The current study realizing that nurses need to increase their awareness and through teaching measures related to risk factors, exercises, diet and treatment that required to enhance patients physical function and should be a part of provided care of patients with hip osteoarthritis for prevention the effects of osteoarthritis on physical function that required and should be a part of the provided care for patients with hip osteoarthritis.

Key Words: Musculoskeletal disorders - Osteoarthritis Hip osteoarthritis - Physical function status Assessment.

Correspondence to: Naglaa F. Abdel Mohsen, The Department of Medical Surgical Nursing, Faculty of Nursing,

Fayoum University, Egypt

\section{Introduction}

MUSCULOSKELETAL disorders (MSDs) are conditions that can affect patient muscles, bones, and joints. It causes pain, discomfort and limited range of motion that interferes with everyday activities, such as walking, climbing stair and have trouble completing the work [1]. Musculoskeletal disorders as osteoarthritis (OA) is known to be a progressive a synovial joint disorder. It can occur in different joints as hip, knee and hand joints which are characterized by pain, stiffness, restricted joint function, difficulty moving and loss of muscle strength. Hip osteoarthritis that is extremely common and the risk increases with age in both males especially after the age of 60 years and female after 40 years old [2] .

Hip osteoarthritis symptoms include morning stiffness, reduced range of hip joint movement, crepitation, damage of the hip cartilage, fatigue, sleep disturbance and also experience social isolation, loss of work and financial difficulty. The hip joint pain is most prominent complain including pain in the lower back, buttocks, and groin, to leg and down into knee, as alike referred pain [3]. Joint pain is initially felt during and after activity, as the disease progresses it may occur with minimal movement or even during rest. Stiff and deformed joint with increasing of pain severity that affects the patient ability to walk, enter or exit a vehicle, sit and getting dressed, enjoy one's day-to-day activities and impact on sports as running, even sleep pattern [4]. Hip osteoarthritis is rapidly increasing the negative effects on hip joint leads to deterioration of the physical function and quality of life in individuals [5]. 
Physical functional status assessment is the most important issue in nursing care for patients with osteoarthritis. The nurse understanding of the disease process and symptoms pattern is critical to the plan of care. A careful initial assessment of the individual patient's health status, concerns, personal concepts and resources that help for reach to health care facilities, as well as additional information about the patient's daily routine, home environment, level of family support, and work status. All of these can enable the nurse to provide a program of activities that can optimally reduce pain and promote maximal function [6]. The nurse is in a key position to assess the patients' problems and needs. Comprehensive physical functional assessment helps the nurse to determine the effects of disease on patient health condition [3,7]. Therefore, the physical functional status assessment must be an integral part in the assessment of the osteoarthritic patients. This provides the nurse and patients with an understanding of osteoarthritis disease [8]. So, the aim of this study is to assess physical functional status among patients with hip osteoarthritis.

\section{Significance of study:}

Near five million adults older than 50 years have hip osteoarthritis [9]. Hip osteoarthritis is a most common public health issue causing chronic disability and impaired mobility of elderly people in most developed countries [10]. Causing different degree of physical difficulties in the performance of every day to day activity in addition to psychological and social aspects of life [11]. The patient is become worse physically and psychologically due to disease symptoms and burden of treatment. [12].

Hip osteoarthritis exacerbates physical functional disabilities and considers as a barrier to selfcare activities as bathing, toileting, and dressing. Stronger incapacitating effects of osteoarthritis make a great impact on physical function and effect on patient's clinical improvements. Also, effect on a patient day by day performance [13]. About $80 \%$ of persons with osteoarthritis have some degree of movement limitation and 25\% cannot perform major daily living activities. Hence, the burden of osteoarthritis on individuals is in terms of its effect on quality of life of the patient [14].

The disease is perceived as a chronic progressive degenerative disease that responsible for pain and degeneration of the hip joint with increasing complain about even simple duties [15]. In hip osteoarthritis, the patient has a different level of difficulties and loss of functioning according to the degree of joint involvement. So, nurses need to know which stage of disease progression and its effects on patients' ability to perform different daily tasks and incidence of functional disability in their lives with this disease [16]. It is hoped that the result of this study will provide nurses with evidenced data to be worked at assessment and rehabilitative level targeted to improving the physical functional status of the osteoarthritis patients, increased access to care, cost savings and empowerment for life activities change. It is also hoped that this research will pave the way for future research collaboration between nurses and other healthcare providers i.e. physicians and physiotherapist.

\section{Patients and Methods}

\section{Setting:}

The current study was carried out at Fayoum University Hospitals in Fayoum governorate from Jan. 2017 - July 2017, including the following departments: (a) Orthopedic outpatient, rheumatoid clinic, and; (b) Orthopedic inpatients ward.

\section{Aim of the study:}

The aim of this study was to assess physical functional status among patients with hip osteoarthritis.

\section{Research question:}

To fulfill the aim of the current study the following research question was formulated: What is the physical functional status among patients with hip osteoarthritis?

\section{Design:}

The descriptive study design was utilized in this study; it is the second broad class of nonexperimental studies. The purpose of descriptive studies is to observe, describe, and document aspects of a situation as it naturally occurs and sometimes to serve as a starting point for hypothesis generation or theory development. Descriptive studies include document the prevalence rate of some condition at a particular point in time and incidence studies that document the frequency of new cases, over a given time period [17].

\section{Sample:}

A convenient purposive sample of 100 adult male and female conscious patients diagnosed with hip osteoarthritis who accept to participate in the study were recruited for the current study. Inclusion criteria: Patients diagnosed with hip osteoarthritis for more than six months, age ranged from 20 
years to above 60 years old, the sample was collected over an anticipated period of six months. Exclusion criteria: Patients on a rehabilitation program and who have medical disorders as mental deterioration, dementia or delirium, neurovascular disorders, osteoporosis, metabolic disorders as diabetes, hyperthyroidism and parathyroid dysfunction were excluded from this study.

\section{Data collection tools:}

The investigators used two tools to gather data pertinent to the study as follows:

Structured interview questionnaire that was developed by the researcher: It was included two parts: (a) Demographic characteristics as age, gender, level of education, marital status, occupation and place of residence; (b) Medical background variables to assess patient medical condition that will include items such as history of present problem, chief complaint, past medical/surgical history, present treatment and body mass index.

Western Ontario McMaster Universities Osteoarthritis Index (WOMAC): Developed by Emeritus Professor Nicholas Bellamy in 1982. It is a valid, reliable and responsive measure of outcome and has been used in diverse clinical and interventional environments. The index has been subject to numerous validation studies (Bellamy, 2016). The (WOMAC) consists of 24 items divided into three subscales: (a) Pain (5 items): During walking, upstairs, at night, at rest, and heavy lifting, (b) Stiffness (2 items): Stiffness after awakening first time at the morning and later in the same day, (c) Physical Function (17 items): Downstairs, upstairs, rising from sitting position, standing, bending on floor, walking on flat surface, getting in/out of a car, going to shopping, putting on/taking off socks, lying in bed, rising from bed, getting in/out of bath, sitting, getting on/off toilet, heavy household duties and light household duties.

WOMAC scoring system: All items of the three domains were measured on a four points Likert scale version. Uses the following scale of difficulty for all items: 0 to 4 , zero indicates no difficulty, one indicates mild difficulty, two indicate moderate difficulty, three indicate severe difficulty and four indicate extreme difficulty. With lower scores indicating lower levels of symptoms or physical disability. These correspond to an ordinal scale of $0-4$. The scores are summed for items in each subscale, with possible ranges as follows: Pain $=$ $0-20$, stiffness $=0-8$, physical function $=0-68$, Total score 96 . Finally, the total score of all subscales was recorded to facilitate interpretation [18]

\section{Validity and reliability:}

Tools were reviewed by a panel of five experts' staff in medical surgical nursing specialty, Faculty of Nursing, Cairo University. Each one of the experts in the panel was asked to examine the instrument for face and content validity. According to reliability the instruments were tested and demonstrated good internal reliability. Tools translated into the Arabic language to ensure uniformity of instructions to participants. The tool reviewed and accepted from the Research Ethical Committee in the Faculty of Nursing, Cairo University. The WOMAC is a more reliable index for use in patients with hip OA. The Cronbach's alphas of the WOM$\mathrm{AC}$ were ranged $0.78-0.95 \mathrm{~m}$ for hip OA. Testretest reliability yielded 0.77-0.94 for hip [19]

\section{Pilot study:}

Once permission was granted to proceed with the proposed study, a pilot study was conducted on $10 \%$ of the sample in the same selected study setting to estimate the needed time for data collection, to judge the feasibility, objectivity, test the ability of the tool to elicit the desired information and to test appropriateness of content, wording and order. No modification was needed; therefore the subjects of the pilot study were included in the actual research subjects.

\section{Ethical considerations:}

An official permission to conduct the study was obtained from the research ethical Committee as well as director of orthopedic outpatient clinic, rheumatoid clinic, and the orthopedic inpatient's ward. Written consent for patients' agreement was obtained after explanation of the nature and purpose of the study. Each patient was free to either participate or not in the current study and had the right to withdraw from the study at any time without any rationale and it will not affect upon care provided. Also, patients were informed that obtained data will not be included in any further researches. Confidentiality and anonymity of each subject were assured through coding of all data.

\section{Statistical analysis:}

Upon completion of data collection through previously mentioned tools, data were computed and analyzed. Data analyses were carried out using the statistical package for social sciences (SPSS), program version 20. All data entries were checked for accuracy against the original raw data of each patient by the investigator. The probability level of 0.01 and 0.05 was adopted as the level of significance for all statistical tests done. 


\section{Results}

Statistical findings of the current study were presented in the following order: The first section is devoted to description of the demographic characteristics and medical back ground variables. The second section presents the result related to WOMAC physical functional assessment tool as pain, stiffness and physical function.

\section{Section I: (a) Demographic characteristics:}

Almost half of patients were mainly male, married $(56 \%$ and $95 \%)$ respectively with the age between 20 and over 65 years with mean of $50.67 \pm 11.14$ years. In addition, less than half of the study subjects (44\%) can read and write. Regarding occupation $(43 \%)$ were housewives, while $(39 \%)$ were laborers. Almost three quarters of the sample were living in rural areas $(79 \%)$.

\section{Section I: (b) Medical Background related Varia- bles:}

$(82 \%)$ of study subjects had gradual disease onset with disease duration, more than 1 year with a mean of $1.88 \pm 0.32$ among ( $88 \%$ ) of study subjects. While $(82 \%)$ of study subjects had no past history, $(8 \%)$ of study subjects have rheumatoid arthritis as a past medical history. Average value of the BMI was $28.12 \pm 4.04 \mathrm{~kg} / \mathrm{m}^{2}$ among $(71 \%)$ of study subjects. In relation to current complain, all subject had more than one complain such as severe pain in hip joint, inability of movements, hip joint stiffness, numbness and hip joint crepitation $(95 \%, 71 \%, 62 \%, 51 \%, 7 \%)$ respectively. Regarding to treatment before hospitalization $(65 \%)$ of the study subjects were treated with medications only while minority of them have different treatments, only (4\%) of them have no treatments.

\section{Section II: WOMAC physical function assessment tool:}

As shown in Table (1), degree of pain is higher on stair climbing, weight bearing then on walking with mean score of $(3.85 \pm 0.47,3.74 \pm 0.71,3.64$ \pm 0.65 ) respectively, while low on the rest with mean sore $(1.94 \pm 0.87)$. In relation to stiffness, mean score of stiffness occurring later on the day more than morning stiffness $(2.67 \pm 1.23,2.44 \pm 0.93)$ respectively.

As shown in Table (2), high mean score among study subjects during ascending stairs, heavy domestic duties, putting on socks, getting in/out of car, taking off socks, getting in/out toilet, getting in/out of bath, and going shopping (3.90 \pm 0.36 , $3.86 \pm 0.42,3.64 \pm 0.78,3.64 \pm 0.81,3.57 \pm 0.81,3.48 \pm$ $0.88,3.41 \pm 0.69$, and $3.34 \pm 0.81$ ) respectively, while mean score was low in light domestic duties (1.91 \pm 1.12$)$.

Regarding Table (3) displayed that statistical significance correlation between age and total physical function score with $(r=0.244)$. In relation to disease onset showed that there was highly statistical significant with total pain score $(r=$ $-0.334-)$. It also illustrate that there was statistical significant between body mass index of the study subjects and total pain score $(r=0.200)$.

It was apparent from Table (4) that there was statistical significant correlation between total pain score and total physical function score with ( $r=$ 0.416 ). Also between total stiffness score and total physical function score with $(r=0.364)$.

Table (1): WOMAC sub-scales mean scores regarding pain and stiffness among the study subjects $(\mathrm{n}=100)$.

\begin{tabular}{ll}
\hline Dimension & Mean \\
\hline Pain on: & \\
Stair climbing & $3.85 \pm 0.47$ \\
Weight bearing. & $3.74 \pm 0.71$ \\
Walking & $3.64 \pm 0.65$ \\
Nocturnal & $2.97 \pm 0.99$ \\
Rest & $1.94 \pm 0.87$ \\
\hline Total & $16.13 \pm 3.69$ \\
\hline Stiffness: & \\
Later on the day & $2.67 \pm 1.23$ \\
Morning stiffness & $2.44 \pm 0.93$ \\
\hline Total & $5.11 \pm 2.16$
\end{tabular}

Table (2): WOMAC sub-scales mean scores regarding physical function among the study subjects $(n=100)$.

\begin{tabular}{ll}
\hline Dimension & Mean \\
\hline Physical function: & \\
Ascending stairs & $3.90 \pm 0.36$ \\
Heavy domestic duties & $3.86 \pm 0.42$ \\
Putting on socks & $3.64 \pm 0.78$ \\
Getting in/out of car & $3.64 \pm 0.81$ \\
Taking off socks & $3.57 \pm 0.81$ \\
Getting in/out toilet & $3.48 \pm 0.88$ \\
Getting in/out of bath & $3.41 \pm 0.69$ \\
Going shopping & $3.34 \pm 0.81$ \\
Bending on floor & $3.27 \pm 1.22$ \\
Rising from bed & $3.10 \pm 0.74$ \\
Standing & $3.06 \pm 0.80$ \\
Lying in bed & $2.98 \pm 0.73$ \\
Rising from sitting & $2.56 \pm 0.91$ \\
Descending stairs & $2.54 \pm 0.90$ \\
Sitting & $2.37 \pm 0.73$ \\
Walking on flat surface & $2.27 \pm 1.30$ \\
Light domestic duties & $1.91 \pm 1.12$ \\
\hline Total & $53.00 \pm 14.01$ \\
\hline
\end{tabular}


Table (3): Correlations of total score of WOMAC with selected variables among study subjects $(n=100)$.

\begin{tabular}{llll}
\hline Variables & $\begin{array}{c}\text { Total pain } \\
\text { score } \\
r(p \text {-value })\end{array}$ & $\begin{array}{c}\text { Total stiffness } \\
\text { score } \\
r(p \text {-value })\end{array}$ & $\begin{array}{c}\text { Total physical } \\
\text { function score } \\
r(p \text {-value })\end{array}$ \\
\hline Age & $.046(0.651)$ & $-.127(0.206)$ & $.244 *(0.014)$ \\
Gender & $.164(0.104)$ & $.152(0.131)$ & $-.175(0.081)$ \\
Occupation & $-.193(0.055)$ & $.029(0.778)$ & $-.010(0.923)$ \\
Disease onset & $-.334 *(0.001)$ & $-.164(0.103)$ & $-.083(0.412)$ \\
Disease duration & $.080(0.427)$ & $-.189(0.060)$ & $-.136(0.178)$ \\
Body mass index & $.200 *(0.046)$ & $.017(0.868)$ & $.122(0.225)$ \\
\hline$*:$ Correlation is significant at the 0.05 level $(2-$ tailed $)$. \\
$* *$ : Correlation is significant at the 0.01 level $(2$-tailed $)$.
\end{tabular}

Table (4): Correlations of total score of WOMAC pain, stiffness with physical functional scores among study subjects $(n=100)$.

\begin{tabular}{ll}
\hline Dimension & $\begin{array}{c}\text { Total physical } \\
\text { function score } \\
r(p \text {-value })\end{array}$ \\
\hline Total pain score & $.416^{* *}(0.000)$ \\
Total stiffness score & $.364^{* *}(0.000)$
\end{tabular}

**Correlation is significant at the 0.01 level (2-tailed).

\section{Discussion}

Discussion of the current study results were presented in the following sequence: (a) The first section is devoted to demographic characteristics and medical background data and (b) The second section presents the data related to WOMAC physical function assessment tool.

Section I: Socio-demographic characteristics and medical background data:

According to demographic characteristics: more than half of the study subject was males and approximately more than one third was females. Many researchers found that among those before 50 years of age, men have a higher prevalence and incidence of general osteoarthritis than women. After age 50, women have a higher incidence and prevalence of general osteoarthritis [20]. Another study reported that the majority of patients were women of age $>50$ years [21]

Their age ranged between 20 -over 65 years old with a mean of $50.67 \pm 11.14$ because of tear and wear process occur in joint with advance in age. The current study is congruent with the study reported that hip osteoarthritis increases in prevalence with age and affects the majority over the age of 65 [22].

More than three-quarter of the studied sample was married, residing in the rural area. Also, more than one-third of the study subjects included was a housewife and hardly able to read and write.
Shortage of medical and educational services in this area, in addition to work in rural areas that may cause strain on joint; all of them may be risk factors of hip osteoarthritis. Many researchers found that high prevalence of osteoarthritis in a rural area of developing countries compared with urban because persons living in high poverty areas have a significantly increased association with osteoarthritis in one or both hips $[23,24]$.

In this study more than two thirds of study subject have gradual disease onset that refers to gradual degenerative effect of osteoarthritis occur with age progression with disease duration of more than 1 year with a mean of $1.88 \pm 0.32$ among more than three quarter of study subjects. No specific study showed that osteoarthritis occur in sudden onset, usually occur gradually as stated in this study that's related to nature of disease pathophysiology of wear and tear process occur with advance in age. Some author concluded that osteoarthritis mainly occurs in later life and tends to be slowly progressive in incidence and can cause significant pain and disability with mean symptom duration of 15.4 years $[25,26]$.

Referring to body mass index more than two thirds of study subject are overweight $(25-29.9 \mathrm{~kg}$ $/ \mathrm{m}^{2}$ ) with a mean of $28.12 \pm 4.04$ because of weight gain increase joint load and degenerative changes. Many researchers concluded that the hip is more likely to be affected by osteoarthritis in people with a higher body mass index (BMI). Also, obesity may predispose to osteoarthritis [27]. Previous findings reflect that obesity is one of the most important risk factors for osteoarthritis in the knee but the relationship between obesity and hip osteoarthritis need more study [28]

In relation to signs and symptoms of rheumatoid arthritis, almost all the study subjects had the classical signs and symptoms that are most characteristic of RA such as severe pain in the hip joint, an inability of movements, hip joint stiffness, numbness, and crepitation. Generally, OA is characterized by cartilage loss, stiffness pain and frequently leads to disability [29].

Section II: Data related to WOMAC physical function assessment tool:

This part presents the WOMAC physical function in relation to dimensions of pain, stiffness and physical function.

Regarding first dimension: Pain: Pain experienced on five different activities; the degree of 
pain is higher on stair climbing, weight bearing than on walking, while low on the rest. This may be caused by continuous stress on the hip joint when upstairs, weight bearing and walking. So, there was a highly statistically significant correlation between the total pain score and disease onset, and BMI. This result coincides with the study stated that worsening of physical function is common with extreme pain as on climbing stairs that is common among patients with osteoarthritis than any other disease [30]. Otherwise findings revealed that more than half of the study sample has moderate difficulty regarding descending stairs with a mean of $2.54 \pm 0.90[\mathbf{2 9}, 31]$.

As regards to second dimension: Stiffness: Mean sore of stiffness occurring in later on the day more than morning stiffness because of stiffness and joint lock more apparent after activities with rest. Some researcher reported that stiffness in the morning or after a period of inactivity is usually present [32]. Also, many authors stated that stiffness after rest is common and as the disease progresses, joint range of motion commonly decreases over time and disability increase [33]

Third dimension, in terms of physical function: The majority of study subjects have extreme difficulty in relation to activities such as ascending stairs, during heavy domestic duties, putting on socks, getting in/out of car, taking off socks, getting in/out toilet, getting in/out of bath and going shopping, while mean score was low in light domestic duties. As mentioned by researcher stated that higher difficulty in physical function is apparent during putting on/off socks [34]. Another study found that patients with hip osteoarthritis have excessive difficulty with getting in or out of bathing and in or out of toilet $[35,36]$. Also, there was a statistically significant correlation between the total pain score, stiffness, age and total physical function score. That is the same stream of some researchers stated that joint range of motion commonly decreases over time and disability may increase, including many functional activities of daily living, such as sitting and getting up from a chair [37] Patients with hip osteoarthritis have activity limitations, balance impairment, and/or gait limitations and associated problems are observed and documented during the physical assessment of the patient [38]. Based on results of the current study, it can be concluded that physical functional status of hip osteoarthritis patients has a significant impact on health status.

\section{Conclusion:}

Based on findings, the current study illustrates those high scores of difficulties in different day to day physical function activities that effect on the patient life and work performance. Most hip osteoarthritis patients suffer from great changes in their activities of daily living (ADL), and the majority found to have some kind of functional limitation, such as stiffness in the later on the day, reduced joint motion, activities regarding ascending stairs, heavy domestic duties, climbing stairs up, standing, walking, squatting, and kneeling. Thus, hip osteoarthritis becomes a very common cause for disabilities, and it is considered a great social problem, as it leads to a higher risk for hospitalization and to high costs to health care services. Studying functional ability is required to support patients' independence, and it has been rising as key to evaluating the health status of patients. Besides that, the inclusion of those patients in rehabilitation programs which focus on the performance of balance-improving exercises, stretching, and strengthening of the most damaged muscle groups could be a feasible measure in order to contribute to the promotion of health among patients with hip osteoarthritis.

\section{Nursing implications and recommendations:}

In the light of the current result, the following recommendations are suggested:

Recommendations related to patients: Establish a center for the patient education, especially for hip osteoarthritis. Rehabilitation program should become an integrated part of the total management of hip osteoarthritis patient.

Recommendations for medical team and hospital administrators:(1) Update knowledge of nurses working in orthopedics departments through attending in services training program, seminar, workshop and scientific conference regarding application of evidence based practice while dealing with patients. (2) Nursing curricula should integrate the concept of comprehensive assessment to determine accurate nursing diagnosis and develop nursing care plan, (3) Nurses and doctors must coordinate their efforts in determining patient's needs and problems, prevention and early detection of hip osteoarthritis patients and helping them to prevent and manage difficulties.

Recommendations for further researches: Replication of the study on a larger probability sample selected from different geographical areas in Egypt is recommended to obtain more generalizable data. 


\section{References}

1- CHERNEY K.: What are Muscloskletal Disorders. Available at http://www. healthline.com/health// musculoskeletal., 2016.

2- SWIFT A.: Osteoarthritis 3: Impact on Patients. Nursing Times, 108 (3): 1-4, 2012.

3- SKEVIN A.J., GRBOVIC V., DIVJAK A., LUCIC A.T., VESELINOVIC M., PAVLOVIC D. and NURKOVIC J.: PARE0003 Assessment of Pain and Importance of Exercise in Hip Osteoarthritis. BMJ Journal, Annual of Rheumatic disease, 76 (2), 2017.

4- LEOPOLD S.S.: Osteoarthritis of the Hip (Hip Arthritis). Orthopedics and Sports Medicine, available at http://. www.orthop.washington.edu, 2015.

5- LOYOLA-SANCHEZ A., RICHARDSON, J., PELAEZBALLESTAS I., ALVAREZ-NEMEGYEI J., LAVIS J.N., WILSON M.G. and WILKINS S.: Physical Function Assessment of a Mayan Population Living With Osteoarthritis: The Importance of Considering Different Aspects of Functioning. Rehabilitation Process and Outcome, 6: $1-9,2017$.

6- HINKLE J.L. and CHEEVER K.H.: Brunner and Suddarth's Text Book of Medical Surgical Nursing. Philadelphia, Wolters Kluwer Health/Lippincott Williams \& Wilkins, 13 th Edition, 39 (8): 1075-1077, 2013.

7- ELLIOTT N., CARSON C., ALLABY M., DOAK B., CARVILL G., THORNTON J., NAIDOO B. and KNOTT L.: Osteoarthritis: The Care and Management of Osteoarthritis in Adults. Osteoarthritis: NICE guideline Draft, 138, 2013.

8- EISMAN J. and MARCH L.: Osteoarthritis Chronic Care Program Model of Care. Musculoskeletal network, pp. 1-44, 2012.

9- LOSINA E. and COLLINS J.E.: Forecasting the Future Pain in Hip OA: Can we rely on pain trajectories?. Osteoarthritis and Cartilage, 24 (5): 765-767, 2016.

10- IIDAKA T., MURAKI S., AKUNE T., OKA H., KODAMA R., TANAKA S. and YOSHIMURA N.: Prevalence of radiographic hip osteoarthritis and its association with hip pain in Japanese men and women: The ROAD Study. Osteoarthritis and Cartilage, 24 (1): 117-123, 2016.

11- XIA B., CHEN D., ZHANG J., HU S., JIN H. and TONG P.: Osteoarthritis Pathogenesis: A Review of Molecular Mechanisms. Calcified Tissue International, 95 (6): 495505,2014

12- HILIGSMANN M., COOPER C., GUILLEMIN F., HOCHBERG M. C., TUGWELL P., ARDEN N. and MARIA-LUISA B.: A Reference Case for Economic Evaluations in Osteoarthritis: An expert consensus article from the European Society for Clinical and Economic Aspects of Osteoporosis and Osteoarthritis (ESCEO). In Seminars in arthritis and rheumatism, December, 44 (3): 271-282. WB Saunders, 2014.
13- DOMINICK C.H., BLYTH F.M. and NICHOLAS M.K.: Unpacking the Burden: Understanding the relationships between chronic pain and comorbidity in the general population. Pain, 153 (2): 293-304, 2012.

14- HUNTER D.J., SCHOFIELD D. and CALLANDER E. The Individual and Socioeconomic Impact of Osteoarthritis. Nature Reviews Rheumatology, 10 (7): 437-441, 2014.

15-MAGNUSSON K. and HAGEN K.B.: Hereditary and Environmental Factors Causing Total Joint Replacement Due to Hip and Knee Osteoarthritis-a Twin Registry Based Prospective Cohort Study. Norsk Epidemiologi, 26 (1-2): 103-106, 2016.

16- GRANT J., LINES L., DARBYSHIRE P. and PARRY Y.: How Do Nurse Practitioners Work in Primary Health Care Settings? A scoping review. International Journal of Nursing Studies, 2017.

17-POLIT D.F. and BECK C.T.: Essential of Nursing Research: Evidence of nursing practice ( 9 th edition), india, wolters Klumber, pp. 223-226, 2012.

18- BELLAMY N.: Western Ontario McMaster Universities Osteoarthritis Index WOMAC. Centre of National Research on Disability and Rehabilitation medicine, University of Queens land, availableat: http://www.rheumatology. org/Rheumatologist/Research/Clinician Researchers, 2016.

29- BASARAN S., GUZEL R., SEYDAOGLU G. and GLULERUYSAL F.: Validity, Reliability and Comparison of the WOMAC Osteoarthritis index and Lequesne Algofunctional Index in Turkish Patients with Hip or Knee Osteoarthritis. Clin. Rheumatol., 29: 749-756. DOI 10.1007/s10067-0101398-2, 2010.

20- ANDERSON, D.W. and RUBASH, H.E.: Etiology of hip osteoarthritis. Available at http://freecontent.lww.com/ wpcontent/uploads/2015/11/ Etiology-of-Hip-Osteo rthritis.pdf, pp. 74 - 75, 2015.

21- DE KLERK B.M., SCHIPHOF D., GROENEVELD F.P., KOES B.W., VAN OSCH, G.J.M., VAN MEURS J.B. and BIERMA-ZEINSTRA S.M.: No Clear Association Between Female Hormonal Aspects and Osteoarthritis of the Hand, Hip And Knee, a Systematic Review, Rheumatology, 48 (9): 1160, 2009.

22- XIA B., CHEN D., ZHANG J., HU,S., JIN H. and TONG P.: Osteoarthritis Pathogenesis: A Review of Molecular Mechanisms. Calcified Tissue International, 95 (6): 495, 2014.

23- PALAZZO C., NGUYEN C., MARTINE M.C., RANNOU F. and POIRAUDEAU S.: Risk Factors and Burden of Osteoarthritis, Annual Physical and Rehabilitation Medicine, 956 (3): 1, 2016

24- FRANSEN M., AGALIOTIS M., BRIDGETT L. and MACKEY M.G.: Hip and Knee Pain: Role of Occupational Factors. Best Practice \& Research Clinical Rheumatology, 25: 83, 2011.

25- COOPER C., DENNI E., EDWARDS M., and LITWIC A.: Epidemiology of Osteoarthritis. Medicographia, 35: 145, 2013.

26- CUSHNAGHAN J. and DIEPPE P.: Study of 500 Patients with Limb Joint Osteoarthritis. Analysis by age, Sex, and Distribution of Symptomatic Joint Sites. available athttp://ard.bmj.com/content/50/1/8.short, Annals of the Rheumatic Diseases, 50 (1): 8, 2017. 
27- HARRIS E.C. and COGGON C.: HIP Osteoarthritis and Work. Best Practice \& Research Clinical Rheumatology, 29: 464, 2015.

28- GROTLE M., HAGEN K.B., NATVIG B., DAHL F.A and KVIEN T.K.: Obesity and Osteoarthritis in Knee, Hip and/or Hand: An epidemiological study in the general population with 10 years follow-up. BMC Musculoskeletal Disorders, 9 (1): 2, 2008.

29- JUDD D.L., THOMAS A.C., DAYTON M.R. and STEVENS-LAPSLEY J.E.: Strength and functional deficits in individuals with hip osteoarthritis compared to healthy, older adults. Disability and rehabilitation, 36 (4): 307, 2014

30- HU B., SKOU S.T., WISE B.L., WILLIAMS G.N., NEVITT M.C. and SEGAL N.A.: Lower Quadriceps Rate of Force Development is Associated with Worsening Physical Function in Adults with or at Risk For Knee Osteoarthritis: 36-month follow-up data from the Osteoarthritis Initiative. Archives of physical medicine and rehabilitation, 2018.

31- ZHANG Y. and JORDAN J.M.: Epidemiology of Osteoarthritis. Clinics in Geriatric Medicine, Clinics Review Articles, 26 (3): 355, 2010.

32- ANDERSON D.W. and RUBASH H.E.: Etiology of hip osteoarthritis. Available at http://freecontent.lww.com/wpcontent/uploads/2015/ 11 /Etiology-of-Hip-Osteorthritis.pdf, pp. 74-75, 2015.
33- MARKS R.: Non operative Management of Hip Osteoarthritis, Pain Studies and Treatment, Scientific Research Publishing, (3): 10, 2015.

34- ABBOTT J.H., HOBBS C., GWYNNE-JONES D. and MOA TRIAL TEAM.: The Short MAC: Minimum Important Change of a Reduced Version of the Western Ontario and McMaster Universities Osteoarthritis Index. journal of orthopaedic \& Sports Physical Therapy, 48 (2): 81-86, 2018.

35- STRAND V., BERGMAN M., SINGH J. A., GIBOFSKY A., KIVITZ A. and YOUNG C.: Low-Dose SoluMatrix Diclofenac in Patients with Osteoarthritis Pain: Impact on quality of life in a controlled trial. Clinical Rheumatology, 36 (6): 1357-1367, 2017.

36- STAMM T.A., PIEBER K., CREVENNA R. and DORNER T.E.: Impairment in the Activities of Daily Living in Older Adults With and Without Osteoporosis, Osteoarthritis and Chronic Back Pain: A secondary analysis of population-based health survey data. BMC Musculoskeletal Disorders, 17 (1): 139, 2016.

37- HUMBY F.C. and ALISON J.: The Test/Retest Reliability of Physical Performance Measures in Osteoarthritis Patients. Int. J. Clin. Rheumatol., 13 (1), 2018.

38- KING L.K., KENDZERSKA T., WAUGH E.J. and HAWKER G.A.: Impact of Osteoarthritis on Difficulty Walking: A Population-Based Study. Arthritis. Care. \& Research, 70 (1): 71, 2018.

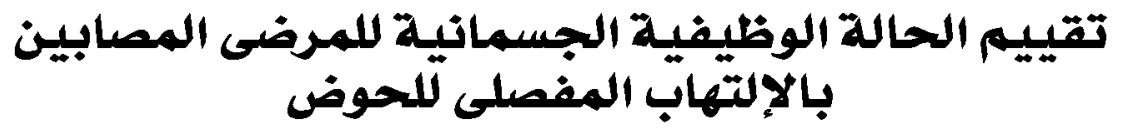

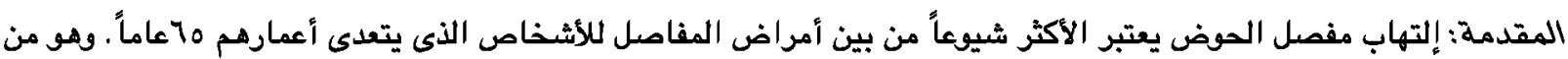

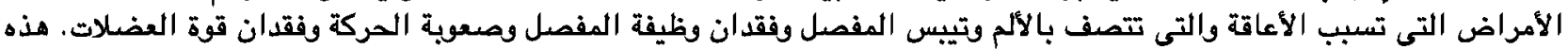

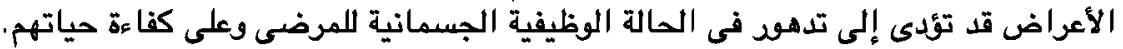

الهدف من الدراسـة: هدفت الدراسة الصالية إلى تقييم الحالة الوظيفية الجسمانية للمرضى المصابين بالإلتهاب المفصلى للحوض.

تصميم الدر اسةّ: تم أستخدام تصميم وصفى لتحقيق الغرض من الدراسة، يسمح التصميم البحثى للباحث بتقييم وقصف وتوثيق

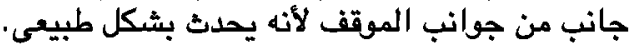
عينة الدراسـة: وقد إثترك فى هذه الدراسة مائة مريض ومريضة مصابين بإلتهاب مفصل الصوض.

أدوات جمع البيانات: تم جمع البيانات المتعلقة بمتغيرات الدراسة من خلال مقابلة منظمة بإستخدام إستبيان صممها الباحث بعد

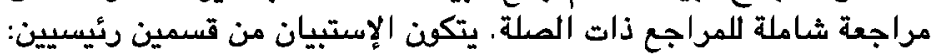

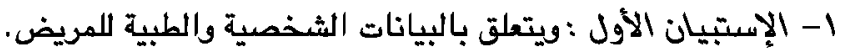
Y- الإستبيان الثانى: هو أداة WOMAC لتقييم الألم والتيبس والحالة الوظيفية الجيسمانية لونية للمرضى.

نتائج الدراسةة: أسفرت النتائج أن هناك علاقة قوية بين مجموع درجات الآلم ودرجات تيبس المفصل مع درجات المات الحالة الوظيفية،

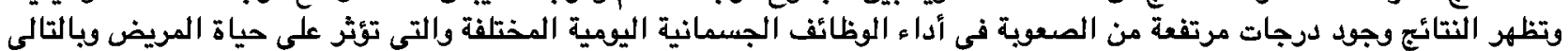

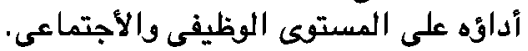

